Symposium on the EPIDEMIOLOGY OF LEPROSY, Geilo, Norway, 1981

Lepr Rev (1981) 52, Suppl I, I-14

\title{
Mycobacterium leprae and the host response
}

\author{
M HARBOE
}

University of Oslo, Institute for Experimental Medical Research, Ullevaal Hospital, Oslo 1, Norway

According to his own recordings, the leprosy bacillus was first seen and recognized as such by Hansen in Bergen on the 28th of February, $1873(1,2)$. His approach was step-wise, severely logical, and epidemiological considerations played a key role in the work leading to hisdiscovery of the bacillus.

At that time, the majority thought that leprosy was hereditary. Others thought that its cause was a "miasma", that is an infectious element which arose from the soil. A contagious origin of the disease was barely discussed in medical circles in Norway at that time. Today the main definition of leprosy, or Hansen's disease, is of course "a chronic disease caused by infection with Mycobacterium leprae." The two other main thoughts of one century ago are still discussed, but in a new context. Today heredity means: to what extent and by which mechanisms do genetic factors influence the tendency to develop clinical disease after exposure to M. leprae? "Miasma", "an infectious element arising from the soil", is today discussed in terms of the effect of environmental mycobacteria on susceptibility to the disease (3), and based on studies and demonstration of mycobacteria in the soil, particularly in Norwegian sphagnum vegetation (4).

Hansen's approach was step-wise. Firstly, he studied the disease from a clinical point of view. In his first two papers published in 1869 and 1870 (5, 6), Armauer Hansen described the results of his anatomical and clinical investigations of leprosy. On the basis of these he drew the conclusion that leprosy was a "specific disease", that is a distinct, well-defined disease and therefore probably with a definite cause.

His next step was epidemiological. In 1871 and 1872 he traveled around in the districts of Western Norway where leprosy was most frequent and carefully investigated 69 families where some of the members suffered from leprosy. He applied strict logic to the various arguments and found that heredity could not account for the observations made, whereas they strongly indicated an infectious origin of the disease.

Through studies of leprosy patients who lived on isolated farms and in whose families no other cases occurred, he learned that these 
patients had always previously been in contact with leprosy cases (1). He further described two cases of newcomers to leprous districts from non-leprous areas who contracted the disease. He found that both had been in contact with leprosy patients before they became ill. In large families he found one segment without leprosy, while others who had moved. and come into contact with leprosy patients got the disease, and he wrote: "This excludes heredity." He also made use of statistics on the number of new leprosy patients in various regions of Western Norway in relation to admissions to hospitals and thus to the effect of partial isolation. When a high proportion of patients with nodular disease were admitted to hospitals, there was a rapidly diminishing number of new cases. The decrease in the number of new cases varied from place to place, and he demonstrated that this corresponded to the rate of admission to hospitals. In regions vhere admission to hospitals was introduced later, there was a delay before fewer new cases occurred (Fig. 2 in reference 2). This became evident in the course of a 15 year period, and his conclusion was: This is too short a period to show an effect on something which is hereditary, but it is on the other hand in very good agreement with infection" (1).

Another epidemiological study made a great impression on Armauer Hansen, namely on the effect of migration of healthy people into a leprosy-endemic area. Drognat-Landré wrote a treatise in 1869 on the basis of his epidemiological studies in Dutch Guiana (7). He found that careful investigation of Europeans who had got leprosy in Surinam strongly indicated that their illness was caused by infectious contact with leprosy patients. Armauer Hansen wrote on this work (8): "In case it should be of general interest, I am happy to state that it was Drognat-Landré's book that made me aware that our research had not paid sufficient attention to the question of infection."

Then began the work of searching for the bacillus. How long it lasted we do not know for certain. He searched in blood and in skin lesions and became keenly aware that he had to work with "nodules covered by unimpaired skin" not to be misled by the occurrence of irrelevant bacteria. On the 28th of February, 1873, he examined a boy with many leprous nodules in the face. He removed one nodule from a nostril, cut through it, carefully scraped the edge of the cut with a knife, rubbed the stuff onto a glass slide, added distilled water to lyse the cells, and observed large numbers of rods escape from the cells. These were the leprosy bacilli! His accurate description of what he observed corresponded closely to what we saw in experiments made 100 years later on the basis of his description (2).

Properties of Mycobacterium leprae

The leprosy bacillus has been classified as a mycobacterium based on different properties which it shares with other mycobacteria, and 
recent biochemical studies on armadillo-grown leprosy bacilli have confirmed that it is a mycobacterium (9). M. leprae does not grow in vitro. This is a negative criterion for species identification. Lack of growth in vitro also means that conventional taxonomic criteria cannot be applied, and its relationship to other mycobacteria is still incompletely known. Immunological criteria thus appear particularly valuable for identification of its taxonomic position $(10,11)$. Our data indicate that $\mathrm{M}$. leprae is more closely related to $M$. tuberculosis, $M$. avium and $M$. lepraemurium that to $M$. nonchromogenicum, M. ph $\overline{l e i}$ and M. smegmatis. Production of $\overline{\text { various }}$ antibodies of defined specificity and directed against selected components of the bacillus (11-13) are crucial for obtaining better means for immunological identification of $\mathrm{M}$. leprae and for studies of its relationship to other mycobacteria. Production of monoclonal antibodies by the hybridoma technology is expected to be particularly valuable, and this approach is actively pursued in several laboratories, including our own.

Table 1. Distinctive properties of Mycobacterium leprae.

1. No growth in vitro on standard media

2. Acid-fastness extracted by pyridine

3. Oxidation of DOPA to quinone

4. Limited growth in the normal mouse footpad with infiltration of nerve tissue

5. Antigenic determinants

Table 1 lists distinctive properties of M. leprae. Staining

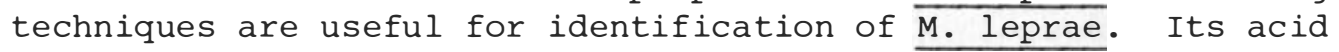

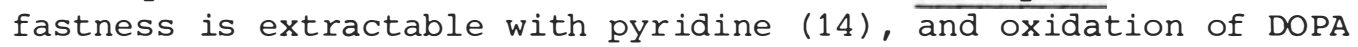
is considered to be a unique property of $M$. leprae since no other mycobacteria tested have been found to oxidise DOPA to quinone $(15,16)$.

Growth of M. leprae in the footpad of the normal mouse (17) is useful for several purposes, including species identification. The combined features of limited, slow growth with infiltration of nerve tisuue are also considered unique for $\mathbf{M}$. leprae.

Animal models

Shepard originally demonstrated (17) local growth of M. leprae in the footpad of the normal mouse with several distinctive features. This model has provided extremely important information on $\underline{M}$. leprae 
itself and the disease. The growth is limited with the number of bacilli reaching a plateau of about $10^{6}$ bacilli per footpad. In the logarithmic phase of multiplication, the generation time of $\mathrm{M}$. leprae is 12-13 days. This prolonged generation time is consistent with the long incubation time and chronicity of leprosy in man. The bacilli infiltrate nerve tissue in the footpad and they have characteristic morphological features as in the human disease (18). Addition of drugs to the diet with subsequent determination of local bacillary growth has been the method of choice for demonstrating the effect of various drugs on multiplication of $M$. leprae in vivo. This technique has been used for screening drugs for potential use in treatment of leprosy (18) and for demonstration of drug resistance (18-20), a major problem in current treatment of leprosy (21).

Rees introduced the thymectomized mouse as an experimental model of leprosy $(22,23)$. Inoculation of living $M$. leprae into thymectomized mice led to the development of a chronic systemic mycobacterial infection, and the yield of acid fast bacilli was at least a thousandfold greater than in the normal mouse. This model clearly established the $\mathrm{T}$ cell dependence of resistance to $\mathrm{M}$. leprae infection. It provided solid data on the mechanisms of reactions in human leprosy, that is episodes with increased inflammatory activity often leading to destruction of nerves due to hypersensitivity against aniigens liberated from $M$. leprae in the nerve tissue. It is also the basis for the demonstration of persisting living bacilli in tissues of leprosy patients even after prolonged treatment with anti-leprosy drugs (24).

Kirchheimer and Storrs demonstrated (25) that M. leprae grows in the nine-banded armadillo. After experimental inoculation of armadillos, many animals develop a generalized mycobacterial infection, often with huge numbers of leprosy bacilli in the tissues. Leprosy bacilli can now be grown in vivo in armadillos and purified in large amounts from armadillo tissue. By removing a previously major restrictive factor, this has introduced an entirely new situation in leprosy research.

M. leprae also grows extensively in the congenitally athymic nude mouse $(26,27)$, as expected from the $\mathrm{T}$ cell dependence of resistance to the infection. The yields reported by Hastings (27) indicate that the nude mice may become an important source of $M$. leprae in addition to the armadillo. Comparisons of the properties of leprosy bacilli grown in armadillos and in nude mice is eagerly awaited. M. leprae in nude mice tissue will probably be of particular value for production of anti-M. leprae by the hybridoma technology since immunization of normal mice of the same strain may be performed without purification of the bacilli, thus avoiding denaturation and loss of antigens inherent in current isolation procedures.

Leprosy in monkeys (28) will be reviewed by Walsh (29). This model is of interest from several points of view. Monkeys may be particularly important for the study of leprosy in a species more closely related to man than other species previously studied, where 
the bacillus is a pathogen in a limited proportion of individuals, thus apparently very similar to the conditions in man. Studies of the effect of various prophylactic procedures, including vaccination, would appear to be particularly relevant in suitable monkey species prior to initiation of field trials in man.

Properties of armadillo-grown M. leprae

Previously M. leprae was only available from nodular tissue of patients with lepromatous leprosy. Lack of $M$. leprae was a severe restriction on leprosy research, and the situation became entirely different after introduction of the armadillo model (25). Antigenic and other studies became possible, and production of armadillo-grown M. leprae has been a major priority in the World Health Organization Immunology of Leprosy (IMMLEP) programme.

In the pre-armadillo era, a few M. leprae antigens were demonstrated. These were a polysaccharide antigen $(30,31)$, the beta and delta antigens of the Gothenburg group (32), and the "nodule extract protein", the NEPR antigen' of Abe et al. $(33,34)$. Recent findings by closs (35) indicate strongly that the latter antigen is not a constituent of $\mathrm{M}$. leprae itself, but an antigen of host origin induced by the granulomatous process.

After armadillo-grown M. leprae became available, we studied the antigenic composition of M. leprae by crossed immunoelectrophoresis (CIE) using sonicates of purified M. leprae for immunization and testing and rabbit antisera as antibody reagent in the top gel. Initially, seven distinct antigenic components of $\mathrm{M}$. leprae were identified (36). CIE is at present the best available technique for precise identification of components of $M$. leprae that are immunogenic and able to induce formation of precipitating antibodies after immunization of rabbits. By the use of concentrated antigen for immunization and testing, more than 20 distinct antigenic components have later been demonstrated in M. leprae (37). We are thus beginning to be able to study the immunogenic components of $\mathrm{M}$. leprae as in other mycobacteria.

Types of immune responses of the host after infection with M. leprae

The response is directed against various constituents, i.e. immunogenic component of the bacillus, and is both a humoral and cellular immune response.

M. leprae is an obligate intracellular parasite. Cell mediated immune reactions have therefore been considered to be of main importance in the defence against the infection (38), and antibodies not to be of importance in this regard. Widely held and reasonable a few years ago, this view now needs to be analyzed in more detail based on the new information on $\mathrm{T}$ cell subsets and cell mediated immune reactions. The response of various $\mathrm{T}$ cell subsets may have 
entirely different effects on the infection:

The reaction of bacterial antigens with sensitized $\mathrm{T}$ cells resulting in liberation of lymphokines and macrophage activa considered to be the main mechanism for control of mycobacterial infection (38). However, stimulation of other $\mathrm{T}$ cells with induction of suppressor mechanisms may directly favour bacterial growth. An imbalance favouring suppressor $\mathrm{T}$ cell activity is currently one of several hypotheses explaining lack of resistance in the multibacillary forms of the disease (39-41).

Specificity of the immune response in leprosy

Specificity is a key feature of an immune response. The importance of the specificity of the immune response in relation to resistance to infection with $\mathrm{M}$. leprae is almost completely unknown. Detailed knowledge on the specificity is, however, essential to understand and analyze the immune response, particularly from an epidemiological point of view.

CIE with patient serum in the intermediate gel is a powerful technique to analyze the specificity of the humoral immune response with regard to $M$. leprae components $1-7$, and the following features have been established in lepromatous leprosy (36): All these components may induce a humoral immune response in human lepromatous leprosy. The specificity varies in individual patients, anti-M. leprae-2, -5 and -7 being the most frequently occurring antibody specificities. Anti-M. leprae-7 antibodies react with different determinants on this component, some of polysaccharide, some of non-polysaccharide nature (42). The specificity of the antibody response in rabbits immunized with $M$. leprae (36) and in armadillos with systemic $M$. leprae infection after experimental inoculation (43) is strikingly similar to that in human lepromatous leprosy.

The specificity of the cell mediated immune reactions is more difficult to study and barely known on component level, since this requires work with isolated, defined components (44).

Immune reactions specific for $M$. leprae

Demonstration of immune reactions specific for $M$. leprae is particularly important if immunological techniques are to be of value in epidemiological studies of leprosy. Strict definitions are required in this area and as a basis for further work.

The term "M. leprae specific antigens" has been widely used. Here we have to distinguish clearly between $M$. leprae specific components and $M$. leprae specific determinants. Further, we are of the opinion that the term "M. leprae specific antigens" should only be used for $M$. leprae specific components.

Criteria for M. leprae specific components are: Firstly, it should be documented that the antigen is of mycobacterial origin. 
This seems self-evident, but to prove that this is the case and to establish suitable controls may be difficult. Since M. leprae does not grow in vitro whereas the mycobacteria used for control are obtained by in vitro culture, antigens of host origin induced by the disease process may easily be mistaken as microbial constituents. The NEPR antigen $(33,34)$ is in fact an example of an antigen induced by the inflammatory process (35). According to our investigations, species specific components are rare in mycobacteria. So far, they have not been convincingly demonstrated in M. leprae, but the lipid antigens studied by Brennan et al. (45) appear to be of particular interest and promise in this regard.

M. leprae specific determinants may be present on components that also contain cross-reacting determinants. Such determinants were first demonstrated by Kronvall et al. (46) using crossed immunoelectrophoresis and lepromatous sera as antibody reagent in the upper gel.

Antibodies reacting with $M$. leprae specific determinants may be demonstrated after absorption with materials prepared from other cross-reacting mycobacteria. The fluorescent antibody absorption test of Abe et al. $(47,48)$ and one of our radioimmunoassays (49) have been specifically designed for this purpose.

Importance of the immune response of the host

Leprosy is an infectious disease. It may to a great extent also be considered as an immunological disease. The causative organism, M. leprae, is virtually non-toxic and may occur in great numbers in the skin with almost no clinical symptoms. Most symptoms of the disease in. fact are due to immune reactions against the bacilli. Complications such as nerve damage which is responsible for the deformities so often associated with the disease, are directly due to cell mediated immune reactions (50-52). The same is the case for erythema nodosum leprosum (ENL) which is a classical example of an immune complex disease in man $(53,54)$.

In addition, the immune response may be of diagnostic significance. This will be a major theme during this symposium, and I will just list a few questions of prime importance in relation to the epidemiology of leprosy:

a. To what extent may subclinical infection be diagnosed by immunological techniques?

b. How is immunological reactivity related to prognosis after infection? And more specifically: to what extent do current tests provide information on the degree of preotective immunity on individual- and population levels in the "native" state or after vaccination?

c. What are the requirements for specificity from an epidemiological point of view under different circumstances? Do current tests meet these requirements? 
Clinical course after infection

The course after infection with $\mathrm{M}$. leprae is highly variable, as illustrated in Fig. 1. More precise information on several points shown in this figure is needed for better understanding of the epidemiology of leprosy.

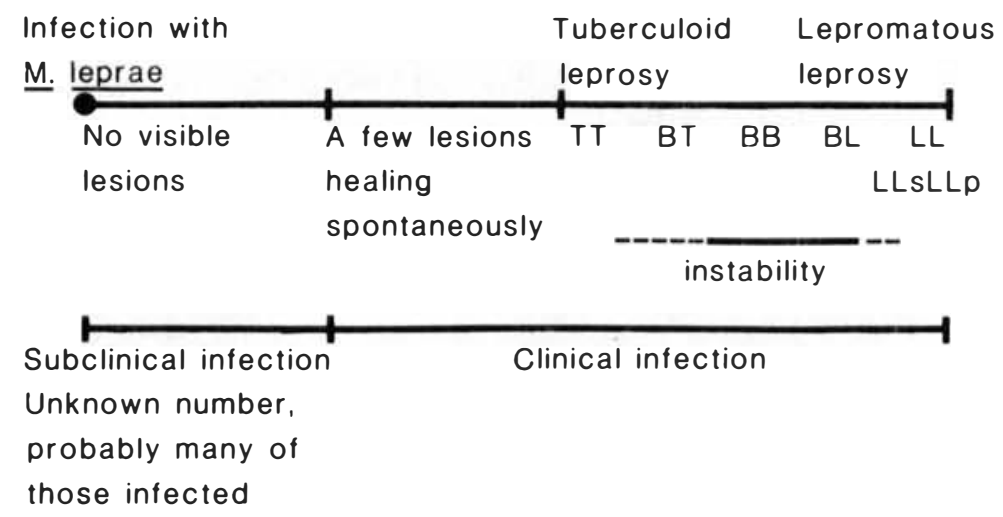

Fig. 1. Course after infection with Mycobacterium leprae.

No clinical signs, i.e. subclinical infection. Evidence of changed immunological reactivity in individuals newly exposed to M. leprae who probably won't develop clinical signs of leprosy was first provided by Godal et al. by the lymphocyte transformation test studying individuals coming from leprosy non-endemic countries to a leprosy hospital in Ethiopia (55). A discussion on the precision of currently available techniques for the diagnosis of subclinical infection and thus for determination of its frequency under different conditions is an essential theme of our symposium.

Lesions healing spontaneously. Undoubtedly this occurs. A proportion of the cases of "indeterminate leprosy" belong to this category. Again, precision and, I believe, improvement of diagnostic procedures and careful follow-up are needed to determine the frequency of this course under different conditions. In other instances, indeterminate leprosy may proceed further to chronic disease.

Classification of patients with persisting disease has been a matter of prolonged discussion and dispute. They constitute a spectrum between two polar groups, tuberculoid leprosy (TT) with few lesions containing few bacilli and lepromatous leprosy (LL) with multiple lesions where the bacilli grow without inhibition due to defective cell mediated immunity. 
Ridley and Jopling's paper (56) "Classification of leprosy according to immunity: A five-group system" is classic. Their system has been widely accepted, and provides good descriptions of variation in clinical course as a basis for accurate clinical diagnosis. It is particularly valuable for research purposes, and many journals require classification according to this system to accept papers for publication.

Under several conditions, however, the system needs simplification.

It needs simplification in field work, often carried out by auxiliary personnel trained for a short period. I presume this means that it needs simplification in the type of work which is the basis of a signigicant part of epidemiological studies of leprosy and in most leprosy control programmes. At the other end, patients with different clinical classification are often pooled to get groups of sufficient size in clinical research work based on careful studies of a limited number of patients.

How should simplification, or pooling of data, be carried out? This question needs to be carefully discussed and considered during our symposium. Data should be pooled and simplified according to the need and current knowledge of the epidemiology of the disease.

In leprosy control programmes in different countries, I have often seen patients with established disease being classified in three groups, called T, B and L for tuberculoid, borderline and lepromatous leprosy. Limited knowldge of classificafion tends to increase the number of individuals in the borderline group. In several immunological studies, patients with BT, BB and BL leprosy have also been considered as one group, again called "borderline."

This is strange and tends to conceal and distort important information.

I see the majority of patients with BT and BL leprosy as basically different with regard to resistance, treatment and amount of bacilli in the lesions and, consequently, of different epidemiological significance. A division in two groups appears more informative in relation to epidemiological studies and leprosy control programmes than to keep the term borderline if the latter implies a continued tendency to apply a three group system. "Two group systems" have appeared in several forms, as indicated in Table 2.

The wHO Expert Committee on Leprosy stated in its fifth report (57) that the Madrid classification is precise enough to meet the requirements for classification of leprosy patients in leprosy control programmes. Hence leprosy cases should be classified as lepromatous, borderline, tuberculoid, and indeterminate. "When leprosy control work is carried out by auxiliary personnel, the classification of borderline leprosy should be omitted and these cases included in the lepromatous group" (58). This simplified version of the Madrid classification is clearly a "two group system" corresponding closely to the next entry in Table 2.

The ILEP form B for Annual Reports (59) lists registered patients in two groups as follows: "Lepromatous patients" 
corresponding to $\mathrm{LL}+\mathrm{BL}+\mathrm{BB}$ in the Ridley and Jopling classification and "Other leprosy patients" comprising patients with BT, TT and Indeterminate leprosy.

In current definition of standard treatment regimens for regular and DDS resistant leprosy cases, different regimens are defined for two main yroups of patients, classified as "multibacillary" and "paucibacillary" which correspond to the two groups in ILEP's form B.

The term "borderline" is difficult to translate into Scandinavian languages. The terms used in Swedish medical schools:

Lepromatous and paralepromatous, and Tuberculoid and paratuberculoid (60) solve this question, but again underline the usefulness of a two-group system in classification and considerations of basic biologic and immunologic features of leprosy patients.

Table 2. "Two-group systems" for classification.

WHO Expert

Committee 1977 on

Leprosy control

ILEP form B,

for registration

of patients

Treatment

regimens

Sweden
Based on Madrid classification

Borderline +

lepromatous

Lepromatous

patients

$\mathrm{LL}+\mathrm{BL}+\mathrm{BB}$

Multibacillary

Lepromatous +

paralepromatous
Indeterminate +

tuberculoid

Other leprosy

patients

$\mathrm{BT}+\mathrm{TT}+\mathrm{I}$

Paucibacillary

Tuberculoid +

paratuberculoid

Extent of variation in parasite and host response

Under standard conditions of inoculation of $\mathrm{M}$. leprae in the footpads of normal or thymectomized mice, the same pattern of multiplication has been obtained by several hundred strains of $\mathrm{M}$. leprae from patients with active disease, irrespective of the clinical type of leprosy, race or region of the world from which they came (18). These observations indicate strongly that the extent of multiplication in vivo is determined by the host response and not by variation in virulence or pathogenicity of the parasite. The evidence for strain variation in M. leprae is meager, although existent $(61,62)$. Variation in host response is profound and responsible for most of the variation in clinical course after infection. Our knowledge of the basis of this variation is only fragmentary. Most studies have been concerned with patients with persisting disease, i.e. late in the process, whereas the events crucial for determination of the subsequent course may occur close to the infection with $M$. leprae 
several years earlier. To a great extent, we even don't know how to study the early events after infection on the individual level.

Epidemiological studies may provide information on variation in events associated with the initial infection and on the probability and extent of superinfection. This information needs to be correlated with determination of clinical course and careful immunological studies at different stages in humans and in experimental models. I expect that collaborative and long term studies of this kind will be mutually rewarding and required to obtain an understanding of leprosy comparable to that of other important infectious diseases.

\section{References}

1 Hansen GA. Undersögelser angående spedalskhedens årsager. Norsk Mag. Laegevid, 1874, 4, 1-88, I-LIII.

2 Harboe M. Armauer Hansen - The man and his work. Int J Leprosy, $1973,41,417-424$.

3 Stanford JL, Paul RC. A preliminary study of the effect of contact with environmental mycobacteria on the pattern of sensitivity to a range of new tuberculins amongst Ugandan adults. J Hyg (Camb), 1976, 76, 205-214.

$4 \mathrm{Kazda} \mathrm{J}$. Non-cultivable mycobacteria in the environment. Lepr Rev, 1981, 52, Suppl 1, 85-91.

5 Hansen GA. Forelöbige Bedrag til spedalskhedens Karakteristik. Nord Med Arkiv, 1869, $1,1-12$.

6 Hansen GA. Fortsatte bī̄rag til lepraens (spedalskhedens) karakteristik. Nord med Arkiv, 1870, 2, Nr 16, 1-32 \&- Nr 21, 1-26.

7 Drognat-Landré CL. De la contagion, seule cause de la lèpre. Paris: 1869.

8 Hansen GA. Om vort kjendskab til spedalskhedens aarsager og om vore forholdsregler mod sygdommen. Norsk Mag Laegevid, 1872, $\underline{2}, 1-37$.

9 Draper P. Cell walls of Mycobacterium leprae. Int J Leprosy, $1976,44,95-98$.

10 Harboe M, Mshana RN, Closs O, Kronvall G, Axelsen NH. Crossreactions between mycobacteria II. Crossed immunoelectrophoretic analysis of soluble antigens of BCG and comparison with other mycobacteria. Scand J Immunol, 1979, 9, 115-124.

11 Widebäk K, KronvallG, Bjorvatn B, Closs O, Harboe M- Comparative studies of antigen 21 in Mycobacterium and Nocardia'species: Possible taxonomic relationships with Mycobacterium leprae. Infect Immun, $1980,30,413-420$.

12 Harboe M, Closs O, Deverill J. Production of monospecific antisera against antigenic components of Mycobacterium bovis (BCG). Scand J Immunol, 1976, $\underline{5}, 861-866$.

13 Harboe $M$, Closs 0 . Immunization with precipitates obtained by crossed immunoelectrophoresis. Scand J Immunol, Suppl 10 (In press). 
14 Convit J, Pinardi M. A simple method for the differentiation of Mycobacterium leprae from other mycobacteria through routine staining techniques. Int J Leprosy, 1972, 40, 130-132.

15 Prabhakaran $\mathrm{K}$, Kirchheimer WF. Use of 3, 4-dihydroxyphenylalanine oxidation in the identification of Mycobacterium leprae. J Bact, 1966, 92, 1267-1268.

16 Haris EB, Prabhakaran $\mathrm{K}$. Uptake of radioactive DOPA by Mycobacterium leprae in vitro. Microbios, 1975, 12, 119-124.

17 Shepard CC. The experimental disease that follows the injection of human leprosy bacilli into foot-pads of mice. J Exp Med, $1960,112,445-454$.

18 Rees RJW, Waters MFR. Recent trends in leprosy research. Brit Med Bull, 1972, 28, 16-21.

19 petit JHS, Rees RJW. Sulphone resistance in leprosy. An experimental and clinical study. Lancet, 1964, 2, 673-674.

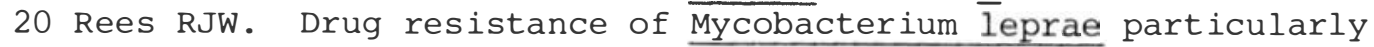
to DDS. Int J Leprosy, 1967, 35, 625-636.

21 Pearson JMH, Cap JA, Haile GS, Rees RJW. Dapsone-resistant leprosy and its implications for leprosy control programmes. Lepr Rev, 1977, 48, 83-94.

22 Rees RJW, Waters MFR, Wedell AGM, Palmer E. Experimental lepromatous leprosy. Nature (Lond), 1967, 215, 599-602.

23 Rees RJW, Weddell AGM. Experimental models for studying leprosy. Ann NY Acad Sci, 1968, 154, 214-236.

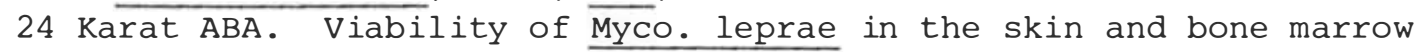
of patients with lepromatous leprosy while on dapsone or lamprene. Lepr Rev, 1975, 46, Suppl, 69-72.

25 Kirchheimer WF, Storrs EE. Attempts to establish the armadillo (Dasypus novemcinctus Linn.)

rosy. I. Report of lepromatoid leprosy in an experimentally infected armadillo. Int J Leprosy, 1971, 39, 693-702.

26 Kohsaka K, Mori $\mathrm{T}$, Ito T. Lepromatoid lesion developed in nude mouse inoculated with Mycobacterium leprae. Animal transmission of leprosy. La Lepro, 1976, 45, 177-187.

27 Hastings RC, Chehl SPK, Morales MJ, Shannon EJ, Kirchheimer WF. Multiplication of acid-fast bacilli in nude mice inoculated with armadillo-derived M. leprae. Int J Leprosy, 1980, 48, 490-491.

28 Leininger JR, Donham KJ, Meyers WM. Leprosy in a chimpanzee. Postmortem lesions. Int J Leprosy. 1980, 48, 414-421.

29 Walsh GP. Leprosy as a zoonosis. Epidemiologic significance. Lepr Rev, 1981, 52, Suppl 1, 77-83.

30 Estrada-Parra S, Calderón-Manes S, Salazar-Mallén M, Amezcua M-E. Isolation of a group-specific polysaccharide from tissues infected with Mycobacterium leprae. Int J Leprosy, 1966, 34, 294-297.

31 Estrada-Parra S. Immunochemical identification of a defined antigen of Mycobacterium leprae. Infect Immun, 1972, 5, 258259.

32 Navalkar RG. Immunologic analysis of Mycobacterium leprae 
antigens by means of diffusion-in-gel methods. Int J Leprosy, 1971, 39, 105-112.

33 Abe M. Studies on the antigenic specificity of Mycobacterium leprae I. Demonstration of soluble antigens in leprosy nodules by immunodiffusion. Int J Leprosy, 1970, 38, 113-125.

34 Abe M, Minagawa F, Yoshino Y, Okamura K. Studies on the antigenic specificity of Mycobacterium leprae II. Purification and immunological characterization of the soluble antigen in leprosy nodules. Int J Leprosy, 1972, 40, 107-117.

35 Closs 0 . Unpublished observations.

36 Harboe M, Closs O, Bjorvatn B, Kronvall G, Axelsen NH. Antibody response in rabbits to immunization with Mycobacterium leprae. Infect Immun, 1977, 18, 792-805.

37 Closs O, Mshana RN, Harboe M. Antigenic analysis of Mycobacterium leprae. Scand J Immunol, 1979, 9, 297-302.

38 World Health Organization. Cell-mediated immunity and resistance to infection. Wld Hlth Org techn Rep Ser, 1973, No 519.

39 Mehra V, Mason LH, Fields J, Bloom BR. Lepromin-induced suppressor cells in patients with leprosy. J Immunol, 1979, 123, 1813 - 1817 .

40 Mehra V, Mason LH, Rothman W, Reinherz E, Schlossman SF, Bloom $\mathrm{BR}$. Delineation of a human $\mathrm{T}$ cell subset responsible for lepromin-induced suppression in leprosy patients. J Immunol, $1980,125,1183-1188$.

41 Stoner GL. Hypothesis: Do phases of immunosuppression during a Mycobacterium leprae infection determine the leprosy spectrum? Lepr Rev, 1981, 52, 1-10.

42 Harboe M, Closs O, Reitan LJ, Draper P. Demonstration of antibodies reacting with different determinants on Mycobacterium leprae antigen 7. Int $J$ Leprosy (In press).

43 Harboe M, Closs O, Rees RJW, Walsh GP. Formation of antibody against Mycobacterium leprae antigen 7 in armadillos. J Med Microbiol, 1978, 11, 525-535.

44 Closs O, Reitan LJ, Negassi K, Harboe M, Belehu A. In vitro stimulation of lymphocytes in leprosy patients, healthy contacts of leprosy patients and subjects not exposed to leprosy. Comparison of an antigen fraction prepared from Mycobacterium leprae and tuberculin purified protein derivative. Scand J Immunol (In press).

45 Brennan PJ, Barrow WN. Evidence for species-specific lipid antigens in Mycobacterium leprae. Int J Leprosy, 1980, 48, 382-387.

46 Kronvall G, Stanford JL, Walsh GP. Studies of mycobacterial antigens, with special reference to Mycobacterium leprae. Infect Immun, 1976, 13, 1132-1138.

47 Abe M, Izumi S, Saito T, Mathun SK. Early serodiagnosis of leprosy by indirect immunofluorescence. Lepr India, 1976, 48, 272-276.

48 Abe M, Yoshino Y, Saikawa K, Saito T. Fluorescent leprosy antibody absorption (FLA-ABS) test for detecting subclinical infection of Mycobacterium leprae. Int J Leprosy, 1980, 48, 109- 
119.

49 Harboe M, Closs O, Bjune G, Kronvall G, Axelsen NH. Mycobacterium leprae specific antibodies detected by radioimmunoassay. Scand J Immunol, 1978, 7, 111-120.

50 Godal T, Myrvang B, Samue $\bar{l}$ DR, Ross WF, Löfgren M. Mechanism of "reactions" in borderline tuberculoid (BT) leprosy. Acta Path Microbiol Scand Sect A Suppl 236, 1973, 45-53.

51 Barnetson RStC, Bjune G, Pearson JMH, Kronvall G. Antigenic heterogeneity in patients with reactions in borderline leprosy. Brit Med J, 1975, 4, 435-437.

52 Bjune G, Barnetson RS̄tC, Ridley DS, Kronvall G. Lymphocyte transformation test in leprosy; correlation of the response with inflammation of lesions. Clin Exp Immunol, 1976, 25, 8594.

53 Wemambu SNC, Turk JL, Waters MFR, Rees RJW. Erythema nodosum leprosum: A clinical manifestation of the Arthus phenomenon. Lancet, 1969, 2, 933-935.

54 Bjorvatn B, Barnetson RS, Kronvall G, Zubler RH, Lambert PH. Immune complexes and complement hypercatabolism in patients with leprosy. Clin Exp Immunol, 1976, 26, 388-396.

55 Godal T, Löfgren M, Negassi K. Immune response to M. leprae of healthy leprosy contacts. Int J Leprosy, 1972, 40, 243-250.

56 Ridley DS, Jopling WH. Classification of leprosy according to immunity. A five-group system. Int J Leprosy, 1966, 34, 255273.

57 WHO Expert Committee on Leprosy, Fifth Report. Wld Hlth Org techn Rep Ser, 1977, No 607.

58 World Health Organization. A Guide to Leprosy Control. Geneva: 1980 , p. 18.

59 ILEP (International Federation of Anti-Leprosy Associations) Form B for annual report on registered patients (point 1.1).

60 Kronvall G. Personal communication.

61 Shepard CC, MCRae DH Hereditary characteristic that varies among isolates of Mycobacterium leprae. Infect Immun, 1971, 3, 121-126.

62 Rees RJW. Personal communication. 